\title{
(6) OPEN ACCESS \\ Method for developing national quality indicators based on manual data extraction from medical records
}

\author{
Melanie Couralet, ${ }^{1}$ Henri Leleu, ${ }^{1}$ Frederic Capuano, ${ }^{1}$ Leah Marcotte, ${ }^{2}$ \\ Gérard Nitenberg, ${ }^{1}$ Claude Sicotte, ${ }^{3}$ Etienne Minvielle ${ }^{1}$
}

${ }^{1}$ Inserm U988, Institut Gustave Roussy, Villejuif Cedex, France ${ }^{2}$ Department of Medicine, University of Washington, Washington, DC, USA

${ }^{3}$ Department of Management, University of Montreal, Montreal, Canada

\section{Correspondence to}

Dr Etienne Minvielle, Inserm U988, Institut Gustave Roussy, 38, rue Camille Desmoulins, Villejuif Cedex 94805, France; Etienne.MINVIELLE@igr.fr

Received 14 May 2012 Revised 31 August 2012 Accepted 7 September 2012 Published Online First 26 September 2012

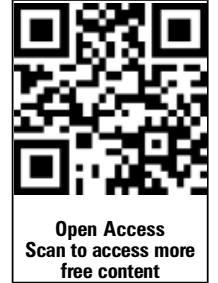

To cite: Couralet M, Leleu H, Capuano F, et al. BMJ Qual Saf 2013;22:155-162.

\begin{abstract}
Developing quality indicators (QI) for national purposes (eg, public disclosure, paying-forperformance) highlights the need to find accessible and reliable data sources for collecting standardised data. The most accurate and reliable data source for collecting clinical and organisational information still remains the medical record. Data collection from electronic medical records (EMR) would be far less burdensome than from paper medical records (PMR). However, the development of EMRs is costly and has suffered from low rates of adoption and barriers of usability even in developed countries. Currently, methods for producing national Qls based on the medical record rely on manual extraction from PMRs.

We propose and illustrate such a method. These QIs display feasibility, reliability and discriminative power, and can be used to compare hospitals. They have been implemented nationwide in France since 2006. The method used to develop these Qls could be adapted for use in large-scale programmes of hospital regulation in other, including developing, countries.
\end{abstract}

\section{INTRODUCTION}

Over the past 10 years, the use of quality indicators (QIs) has been strongly encouraged as a means of assessing quality in hospitals. QIs are now a widely used tool in hospital regulation in developed countries (eg, in performance-based financing and the public disclosure of hospital comparisons). ${ }^{1}$

It is well established that key attributes of QIs are able to detect targeted areas for improvement on topics of importance, scientific soundness and feasibility. ${ }^{2}$ For national comparisons of healthcare organisations (HCO), a valid and standardised data collection process is also required, as any errors could affect a hospital's reputation and also have financial repercussions. Three main data sources are used to develop QIs: (1) ad hoc surveys (eg, patient's experience and satisfaction indicators), but these are costly and require recruitment of respondents and high hospital commitment, ${ }^{3}$ (2) medico-administrative data (eg, patient safety indicators), but these often capture limited information on complex care processes ${ }^{4}$ and (3) medical records (eg, clinical practice and organisational indicators) which are the preferred option for obtaining accurate and reliable clinical and organisational information. ${ }^{5-9}$

Most medical records are still paper medical records (PMRs) and entail difficulties in terms of data extraction that remains manual. ${ }^{10}$ The adoption of interoperable electronic medical record (EMR) systems could promote efficiency by developing an automated process of data extraction. However, it is expensive. Moreover, in the most highly developed countries that invest in this area, it remains arduous. For instance in US hospitals, only 13\% reported use of a basic EMR system in 2008 , according to a study by Jha et al. ${ }^{11}$ Although these numbers have significantly increased over the last few years-2011 data shows 35\% adoption of basic EMR systems by US hospitals - the rates of adoption are still low. ${ }^{12}$ A recent national study shows that in France only 6\% of medical records are fully electronic. ${ }^{13}$ In terms of data extraction for the purposes of quality measurement, a basic EMR system does not necessarily enable easy and automatic computation of aggregated data, nor does it preclude the use of partial paper charts, making some data completely inaccessible via the EMR.

We propose a pragmatic method for using PMRs to produce national QIs that 
display feasibility, reliability and discriminative power, and that enable PMR audits for hospital comparison. The method is based on data extraction from a random sample of PMRs in each hospital. It has been implemented in France since 2006, but could be adopted by other countries interested in assessing large-scale hospital performance. ${ }^{14}$ We describe the methods development, the PMR sampling strategy and the statistical procedures for ensuring robustness. Each step of the method is illustrated with appropriate examples. Last, we discuss the place of such a method in the context of development of EMR systems.

\section{BACKGROUND TO METHOD DEVELOPMENT AND IMPLEMENTATION}

The method was developed and has been implemented by the COMPAQH project team (COordination for Measuring Performance and Assuring Quality in Hospitals), a French national initiative for the development and use of QIs, coordinated by the French Institute for Health and Medical Research (INSERM) and sponsored by the Ministry of Health and the French National Authority for Health (Haute Autorité de Santé, HAS). ${ }^{13} 15$

The QIs were selected and designed with the collaboration of the French public authorities and health professionals. Each is categorised within nine priority areas for quality improvement: (1) pain management; (2) continuity of care; (3) management of patients with nutritional disorders; (4) patient safety; (5) taking account of patients' views; (6) implementation of practice guidelines; (7) promoting motivation, accountability and evaluation of skills; (8) access to care and (9) coordination of care.

Eight of the nine priority areas were selected in 2003 after a thorough literature review, survey of international initiatives and consensus process among healthcare policy makers, healthcare professionals and consumers. The ninth was added in 2009. After defining healthcare priorities, QIs were identified within each area. Following literature review, 81 QIs were selected, and were then subjected to evaluation by healthcare professionals based on three dimensions: feasibility, importance, coherence with existing initiatives. A two-round Delphi method was used in order to select a first set of QIs to be developed and tested. In 2009, with the inclusion of a new priority area, this list was reviewed. QIs that were deemed to be 'topped out', or no longer priority measures, were discarded and new QIs were added. As a result, 42 QIs were selected for retooling and further development. ${ }^{16}$

Since 2006, 24 QIs developed by COMPAQH have been implemented nationwide (depending on the topic, among the $3000 \mathrm{HCOs,} \mathrm{including} 1300$ acutecare organisations). Of the 24 QIs, 16 are based on PMRs, six on administrative data extracted from a national database, and two are based on an ad hoc survey (table 1).

Ten QIs were discarded because of low acceptance or poor metrological qualities. ${ }^{17}$ We shall use the results for the first six QIs to illustrate the methodology and the challenges encountered during development and implementation (table 2).

\section{MEDICAL RECORD SAMPLING STRATEGY}

First, the QIs must be designed; a process that employs the collaboration of healthcare professionals and their representatives, in efforts to ensure face-to-face and content validation among stakeholders. After this stage, sufficient and accurate data need to be obtained for QI measurement. Our data collection method is based on manual data extraction from a random sample of 60-80 PMRs per hospital. The sample size needs to be small to limit workload and contain costs (feasibility). However, it also needs to be large enough to ensure reliability (ie, reproducible results for a fixed set of conditions irrespective of who makes the measurement) and discriminative power (ie, ability to detect overall poor quality and/or variations in quality among hospitals statistically). ${ }^{18} 19$ Discriminative power is crucial in order that public reporting and paying-for-performance mechanisms act as incentives for local quality improvement initiatives. Whenever possible, the same set of PMRs is used to measure several QIs.

\section{QI FEASIBILITY, RELIABILITY AND DISCRIMINATIVE POWER}

To ensure method validity, we assessed the metrological qualities of the QIs in a pilot test on 50 to more than 100 hospitals (depending on the QI). Three criteria were taken into account in the selection of hospitals: geographical area, volume of activity and status (teaching, public, private-non-profit and private-for-profit).

\section{Feasibility}

Poor data collection can diminish the metrological qualities of QIs. We used a 30-item standard grid to assess five dimensions of feasibility (acceptability, workload, understanding of QI implementation, professional involvement and organisational capacity including IT systems) in the pilot test. ${ }^{20-22}$ The grid was assessed in each pilot hospital by the health professional in charge of the data collection. In general, for each feasibility dimension, the total number of problems encountered was calculated. We considered a 'no feasibility' issue as under $5 \%$ of problems, 'middle feasibility' issue between $5 \%$ and $10 \%$ of problems, and a 'feasibility' issue up to $10 \%$ of problems. The feasibility problems encountered were then discussed in an expert panel before validating the content of each QI. In the pilot test, the highest incidence of feasibility problems was encountered with 
Table 1 The 42 Qls developed for nationwide use in France

\begin{tabular}{|c|c|c|c|c|c|c|c|c|}
\hline & \multirow[b]{2}{*}{$\begin{array}{l}\text { Date of } \\
\text { selection }\end{array}$} & \multirow[b]{2}{*}{$\begin{array}{l}\text { Priority } \\
\text { area }\end{array}$} & \multirow[b]{2}{*}{$\begin{array}{l}\text { Data } \\
\text { source }\end{array}$} & \multicolumn{4}{|c|}{ Type of hospitals concerned } & \multirow[b]{2}{*}{$\begin{array}{l}\text { Introduced } \\
\text { in* }\end{array}$} \\
\hline & & & & $\mathrm{AC}$ & Rehab. & Psy & $\begin{array}{l}\text { Home } \\
\text { care }\end{array}$ & \\
\hline \multicolumn{9}{|l|}{ (a) Indicators in nationwide use $(n=24)$} \\
\hline Consumption of antibiotics per 1000 patient-days & 2003 & 4 & Admin & $x$ & $x$ & $x$ & & 2006 \\
\hline $\begin{array}{l}\text { Composite index for evaluation of activities against } \\
\text { nosocomial infections }\end{array}$ & 2003 & 4 & Admin & $x$ & $x$ & $x$ & & 2006 \\
\hline Rate of surgical site infections (SURVISO) & 2003 & 4 & Admin & $x$ & & & & 2006 \\
\hline $\begin{array}{l}\text { Rate of methicillin-resistant Staphylococcus aureus } \\
\text { per } 1000 \text { patient-days }\end{array}$ & 2003 & 4 & Admin & $x$ & $x$ & & & 2006 \\
\hline $\begin{array}{l}\text { Annual volume of alcohol-based products (gels and } \\
\text { solutions) per patient-day }\end{array}$ & 2003 & 4 & Admin & $x$ & $x$ & $x$ & & 2006 \\
\hline Conformity of anaesthetic records & 2003 & 2 & PMR & $x$ & & & & 2008 \\
\hline $\begin{array}{l}\text { Delay in sending hospitalisation summary to general } \\
\text { practitioner }\end{array}$ & 2003 & 9 & PMR & $x$ & & & & 2008 \\
\hline Screening for nutritional disorders in adults & 2003 & 3 & PMR & $x$ & & & & 2008 \\
\hline Medical record content & 2003 & 2 & PMR & $x$ & & & & 2008 \\
\hline Traceability of pain assessment & 2003 & 1 & PMR & $x$ & & & & 2008 \\
\hline $\begin{array}{l}\text { Hospital care of myocardial infarction after the acute } \\
\text { phase }(8 \mathrm{QIs}) \dagger\end{array}$ & 2003 & 6 & PMR & $x$ & & & & 2008 \\
\hline $\begin{array}{l}\text { Compliance of patient records in rehabilitation } \\
\text { hospitals (4 Qls) }\end{array}$ & 2009 & 2 & PMR & & $x$ & & & 2009 \\
\hline Traceability for risk assessment of pressure ulcers & 2009 & 6 & PMR & $x$ & $x$ & $x$ & & 2009 \\
\hline Multidisciplinary meetings in oncology & 2003 & 2 & PMR & $x$ & & & & 2010 \\
\hline Conformity of orders for imaging tests $\ddagger$ & 2003 & 2 & PMR & $x$ & $x$ & & & 2010 \\
\hline Compliance of patient records in homecare (5 Qls) & 2009 & 2 & PMR & & & & $x$ & 2010 \\
\hline Compliance of patient records in psychiatry (3 Qls) & 2009 & 2 & PMR & & & $x$ & & 2010 \\
\hline $\begin{array}{l}\text { Prevention and management of postpartum } \\
\text { haemorrhage ( } 5 \mathrm{Qls})\end{array}$ & 2009 & 6 & PMR & $x$ & & & & 2012 \\
\hline Support for haemodialysis patients (X QIs) & 2009 & 6 & PMR & $x$ & & & & 2012 \\
\hline Initial hospital treatment of stroke (6 Qls) & 2003 & 6 & PMR & $X$ & & & & 2012 \\
\hline Satisfaction in hospitalised patients & 2003 & 5 & Survey & $x$ & & & & In progress \\
\hline Waiting time for external consultation & 2003 & 8 & Admin & $x$ & & & & In progress \\
\hline Organisational support for breast cancer & 2003 & 6 & PMR & $x$ & & & & In progress \\
\hline $\begin{array}{l}\text { Architectural, ergonomic and informational } \\
\text { accessibility }\end{array}$ & 2003 & 8 & Survey & $X$ & $x$ & $x$ & & In progress \\
\hline \multicolumn{4}{|l|}{ (b) Indicators in development $(n=8)$} & \multicolumn{2}{|c|}{$\begin{array}{l}\text { Priority } \\
\text { area }\end{array}$} & \multicolumn{3}{|c|}{ Data source } \\
\hline \multicolumn{3}{|l|}{ Organisational climate } & & \multicolumn{2}{|l|}{7} & \multicolumn{3}{|c|}{ Survey } \\
\hline \multicolumn{3}{|l|}{ Emergency timeout } & & \multicolumn{2}{|l|}{8} & \multicolumn{3}{|c|}{ Admin } \\
\hline \multicolumn{3}{|l|}{ Evaluation of patient complaints and claims } & & \multicolumn{2}{|l|}{5} & \multicolumn{3}{|c|}{ Admin } \\
\hline \multicolumn{3}{|l|}{ Detection of alcohol-dependent patients } & & \multicolumn{2}{|l|}{6} & \multicolumn{3}{|l|}{ PMR } \\
\hline \multicolumn{3}{|l|}{ Patient experience } & & \multicolumn{2}{|l|}{5} & Surve & & \\
\hline Obesity surgery in adult & & & & 6 & & PMR & & \\
\hline Composite score of professionals coordination on acu & stroke mana & tt patients & & 9 & & Admi & & \\
\hline Composite score of emergency department assessmen & & & & 8 & & Admi & & \\
\hline (c) Discarded indicators $(n=10)$ & & & & & & & Priority & \\
\hline Absence of short-term professionals in contact with th & patient & & & & & & 7 & \\
\hline Turnover of professionals in direct contact with the pa & & & & & & & 7 & \\
\hline Cancellation of procedures involving anaesthesia in ar & bulatory care & & & & & & 2 & \\
\hline Violence in psychiatry & & & & & & & 4 & \\
\hline Deadline for appointments in medico-psychological ce & tres & & & & & & 8 & \\
\hline Management of treatment side-effects & & & & & & & 6 & \\
\hline Electroconvulsive therapy & & & & & & & 6 & \\
\hline
\end{tabular}




\begin{tabular}{|c|c|c|c|c|c|c|c|c|}
\hline & \multirow[b]{2}{*}{$\begin{array}{l}\text { Date of } \\
\text { selection }\end{array}$} & \multirow[b]{2}{*}{$\begin{array}{l}\text { Priority } \\
\text { area }\end{array}$} & \multirow[b]{2}{*}{$\begin{array}{l}\text { Data } \\
\text { source }\end{array}$} & \multicolumn{4}{|c|}{ Type of hospitals concerned } & \multirow[b]{2}{*}{$\begin{array}{l}\text { Introduced } \\
\text { in* }\end{array}$} \\
\hline & & & & $A C$ & Rehab. & Psy & $\begin{array}{l}\text { Home } \\
\text { care }\end{array}$ & \\
\hline Death in low-mortality diagnosis-related groups & & & & & & & 4 & \\
\hline Hospitalised patients with a social management & & & & & & & 2 & \\
\hline Prevention of falls in hospitalised patients & & & & & & & 4 & \\
\hline
\end{tabular}

*The year of national introduction. From the introduction, the QI is mandatorily reported each year by all hospitals concerned (except for 'Conformity of orders for imaging tests' QI which is not mandatory).

tDepending on the theme, one or more Qls were developed; we count 1 QI for 1 theme.

¥The only one that is not mandatory.

AC, acute care; Admin, administrative data-based; PMR, paper medical record; Psy, psychiatric care; QI, quality indicator; Rehab., rehabilitation care; Survey, ad hoc survey.

the acute myocardial infarction (AMI)-related QI $(11 \%$ vs $4.9 \%$ for 'quality and content of anaesthetic records', and $3.2 \%$ or less for the other QIs). The dimension concerned was 'professional involvement'. Originally, it was stipulated that a health professional of the specialty (eg, a cardiologist) must be involved

Table 2 Details of the first 6 Qls in nationwide use in France in acute-care hospitals

\begin{tabular}{|c|c|c|}
\hline QI & $\begin{array}{l}\text { Number of records in } \\
\text { random sample }(n)^{*}\end{array}$ & Calculation \\
\hline Traceability of pain assessment & $80 \dagger$ & $\begin{array}{l}\text { Proportion of records containing at least one pain assessment result (number of } \\
\text { records with at least one result/n) }\end{array}$ \\
\hline $\begin{array}{l}\text { Quality and content of the medical } \\
\text { record }\end{array}$ & $80+$ & $\begin{array}{l}\text { Composite score (compliance with } 10 \text { items): presence of: surgical report, delivery } \\
\text { report, anaesthetic record, transfusion record, outpatient prescription, outpatient } \\
\text { record, admission documents, care and medical conclusions at admission, and drug } \\
\text { prescriptions during stay; overall medical record organisation }\end{array}$ \\
\hline $\begin{array}{l}\text { Quality and content of the anaesthetic } \\
\text { record }\end{array}$ & 60 & $\begin{array}{l}\text { Composite score (compliance with } 13 \text { items). Presence of the following information: } \\
\text { Preanaesthesia: patient name, anaesthetist name, information on } \\
\text { preanaesthesia visit, treatments, risk evaluation, type of anaesthesia, } \\
\text { evaluation of access to upper airways } \\
\text { Peranaesthesia: anaesthetist name, technique of access to upper airways } \\
\text { Postintervention: anaesthetist name, discharge from recovery room, drug } \\
\text { prescriptions } \\
\text { Perianaesthesia: adverse events }\end{array}$ \\
\hline
\end{tabular}

Time elapsed before sending discharge $\quad 80 \dagger$

letters

Screening for nutritional disorders

Management of acute myocardial infarction at hospital dischargeł (8 QIs)
Proportion of records containing a letter sent to the patient's general practitioner within 8 days (number of records containing a letter/n)

Proportion of records giving body weight (BW) at admission (number of records with $\mathrm{BW} / \mathrm{n}$ )

$60 \quad$ Proportion of records

1. With prescription for an antiplatelet drug (number with prescription+number justifying absence of prescription $/ \mathrm{n}$ )

2. With prescription for a beta-blocker (number with prescription+number justifying absence of prescription $/ \mathrm{n}$ )

3.1. With left ventricular ejection fraction (LVEF) measurement (number with LVEF/N)

3.2. With LVEF $<40 \%$ and prescription for an angiotensin-converting enzyme inhibitor (number of records with prescription/number of records with LVEF $<40 \%)$

4.1. With prescription for a statin (number with prescription+number justifying absence of prescription $/ n$ )

4.2. With prescription for a statin and order for lipid test (number of records with an order/number of records with a prescription)

5. With advice on diet (number of records with advice/n)

6. Of patients with a history of cigarette smoking who received advice on giving up (number of records with advice/number of records for patients with history of cigarette smoking)

*Previous year records for patients hospitalised for more than 1 day.

tSame sample used to measure 4 Qls.

$\ddagger$ Patients who died in hospital were excluded.

QI, quality indicator. 
in the data collection process, but during the pilot test, it was difficult to achieve this aim for all hospitals. The average time spent on data collection was 8.5 days per hospital for the five QIs related to medical or anaesthetic record content, and 5 days for AMI QIs (including sample of the medical records, retrieval from archives, abstraction of the sample, data entry in the computer and verification of data quality). As a result, a national generalisation committee was created, which meets each year, and whose discussions include difficulties, including feasibility, encountered by hospitals during generalisation. Currently, no intrinsic limitation of feasibility has been reported for this or any other QI during nationwide generalisation. ${ }^{23}$

\section{Reliability}

Interobserver reliability is essential for standardised manual data collection. The reliability of our method was tested by double-data capture of 20 PMRs by two independent observers in 10 hospitals. Observer agreement, as given by the Kappa coefficient, was in the range $0.80-0.96$ for each QI.

\section{Discriminative power}

A QI should be able to detect room for improvement in clinical care. We routinely perform two tests: (1) the QI results obtained are first tested using Student's $t$ test or Wilcoxon signed-rank test against an optimal threshold (100\%). If the difference is significant (at $0.05 \%$ ), the mean QI is below the desired threshold and (2) the dispersion of QI values among hospitals is tested using the Gini coefficient. This coefficient is a measure of statistical dispersion that is commonly used in economics to describe inequalities across groups. ${ }^{24} 25$ It is a ratio ranging from zero (maximum dispersion) to 1 (no dispersion).

Table 3 gives the mean overall scores for each QI in our pilot study. Scores for all QIs varied widely across hospitals (Gini coefficient $<0.5$ ) except for 'order of a lipid test' (AMI 4.2 in table 3). This QI had a mean score $(6.9 \%)$ far below the theoretical threshold of $100 \%(\mathrm{p}<0.001)$. For each QI, performance (mean overall score) was significantly lower than the optimal threshold of $100 \%(p<0.001)$. Taken together, these results provide evidence for good discriminative power.

\section{HOSPITAL RANKING}

Our QI scores are computed together with their uncertainty, that is, the 95\% CI around the mean score. The CI is estimated using the 'Central limit theorem' which assumes normal distribution of scores for item numbers above 30 . The CI thus depends on the number of PMRs. Because of this, hospitals were ranked according to the Hospital Report Research Collaborative method into three categories (top, neutral, bottom) on the basis of the overall mean for all hospitals, and the 95\% CI calculated for a normal distribution. ${ }^{26}$ Hospitals with fewer than 30 PMRs were excluded. Hospital distribution into the three categories was similar during the pilot test and after nationwide QI generalisation, except for 2 QIs, namely, 'time elapsed since sending discharge letters' and 'screening for nutritional disorders' $(\mathrm{p}<0.001)$ The difference was in favour of the pilot test (figure 1).

\section{DISCUSSION}

We propose a method for developing QIs for nationwide hospital comparisons based on manual data extraction from PMRs. Our key concern is reducing the workload as far as possible without detracting from the validity of the statistical comparisons among hospitals. We achieved this by selecting the smallest PMR sample (60-80) that can discriminate among hospitals, by using the same set of PMRs to measure several QIs whenever possible, and by discarding QIs that had shown poor metrological qualities in a

Table 3 Results for the 6 Qls during pilot testing

\begin{tabular}{|c|c|c|c|c|c|}
\hline \multirow[b]{2}{*}{ QI } & \multirow[b]{2}{*}{ Hospitals (n) } & \multicolumn{3}{|c|}{ Score $(\%)$} & \multirow[b]{2}{*}{ Gini coefficien } \\
\hline & & Min & Max & Mean (SD) & \\
\hline 1. Quality and content of the medical record & 112 & 36.9 & 89.9 & $64.2(10.8)$ & 0.09 \\
\hline 2. Screening for nutritional disorders & 128 & 0 & 96.8 & $66.4(22.6)$ & 0.2 \\
\hline 3. Time elapsed before sending discharge letter & 133 & 9 & 91 & $52.7(18.2)$ & 0.2 \\
\hline 4. Letters Quality and content of the anaesthetic record & 86 & 33.2 & 92.8 & $65.6(12.4)$ & 0.1 \\
\hline 5. Traceability of pain assessment & 133 & 0 & 98.7 & $39.8(27.8)$ & 0.4 \\
\hline 6.1. AMI 1 & 55 & 20 & 100 & $90.9(11.9)$ & 0.05 \\
\hline 6.2. AMI 2 & 55 & 47.1 & 100 & $84.6(12.3)$ & 0.08 \\
\hline 6.3. AMI 3.1 & 55 & 45 & 100 & $87.7(11.7)$ & 0.07 \\
\hline 6.4. AMI 4.1 & 55 & 72.7 & 100 & $89.2(6.9)$ & 0.04 \\
\hline 6.5. AMI 4.2 & 55 & 0 & 100 & $14.5(23.8)$ & 0.7 \\
\hline 6.6. AMI 5 & 55 & 0 & 93.3 & $33.7(27)$ & 0.4 \\
\hline
\end{tabular}

AMI, acute myocardial infarction; QI, quality indicator. 


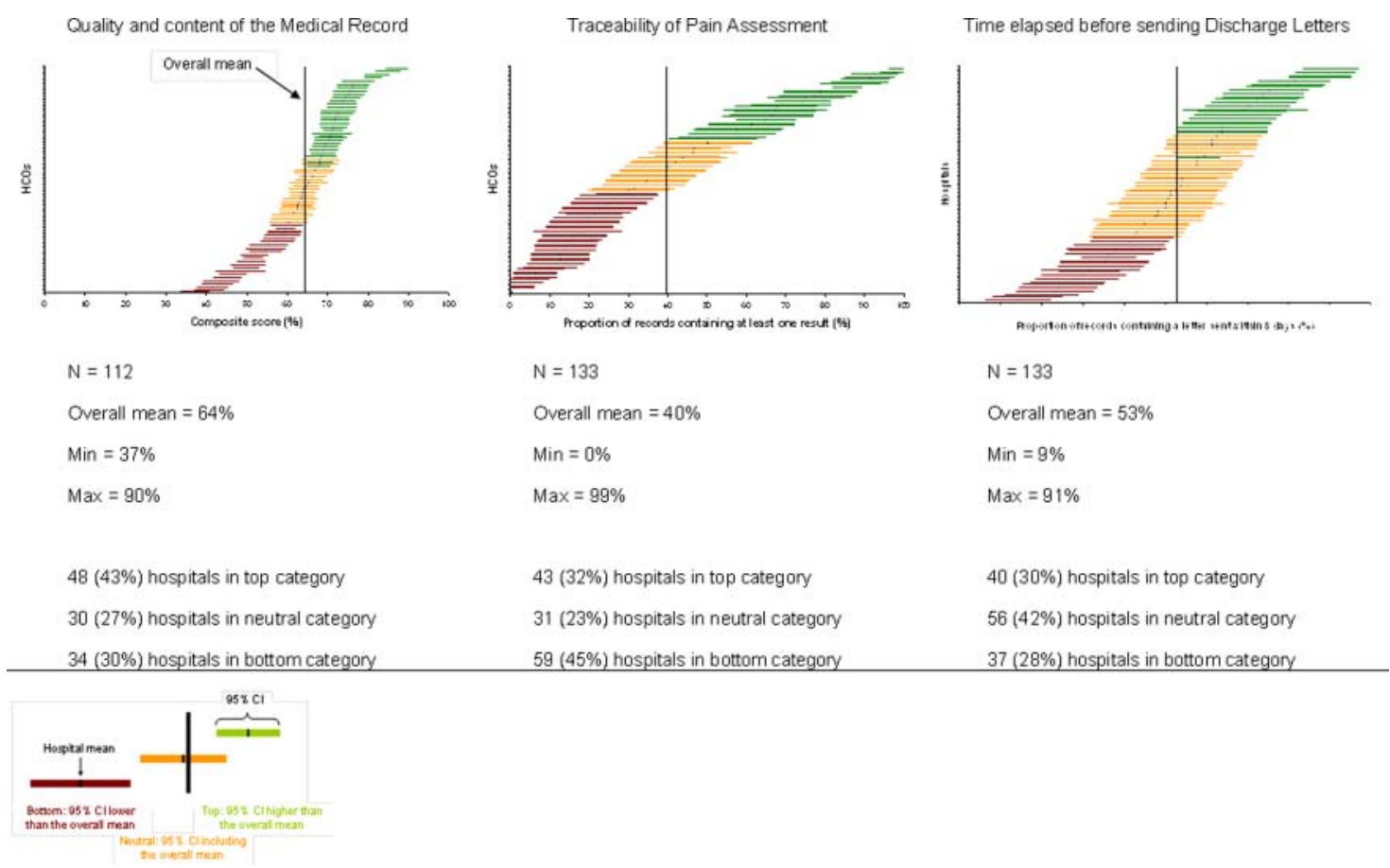

Figure 1 Variability in score for 'quality and content of the medical record', 'traceability of pain assessment' and 'time elapsed before sending discharge letters' during pilot testing. The horizontal line gives the mean score for each hospital (with $95 \% \mathrm{CI}$ ). The vertical line represents the overall mean score for all hospitals. The number and percentage of hospitals in each ranking category are given.

low-cost pilot test of feasibility, reliability and discriminative power.

\section{Strengths of the method}

Our method was adopted in France in 2006, and has led to the nationwide implementation of an increasing number of QIs. Public reporting of 1200 acute-care hospitals based on these QIs has been available since 2008 on the website of the French Ministry of Health. ${ }^{15}$ The method has three strengths: (1) the close collaboration of health professionals and their representatives in QI development, from the QI design and definition stage to feasibility testing, auditing and validation of any changes made, facilitates QI acceptability, appropriation of audit results and the introduction of quality improvement initiatives; (2) feasibility, reliability and discriminative power were assessed in a low-cost pilot test, which means that each year a new set of QIs can be prepared for generalisation and (3) QIs yielding poor results could be discarded before generalisation.

\section{Limitations}

Our study has limitations. The preset PMR sample size, regardless of the hospital's volume of activity, might introduce a bias. The bias and likelihood of an erroneous classification were limited by combining two approaches: (1) by introducing uncertainty (Van Dishoeck et al recently showed how, depending upon the method used, account can be taken of uncertainty ${ }^{27}$ ) and (2) by comparing three categories of hospitals rather than individual hospitals. A second limitation concerns the quality of the data in the PMR sample. Some gaming behaviour and some observerdependent variability may persist in the data collection process. An ex-post control could be carried out in a sample of hospitals to address this limitation. A third limitation is the fact that this methodology can be time consuming, which limits the number of QIs nationally introduced each year. In order to mitigate this effect, we developed some specific strategies, such as having common collected data for multiple QIs, and a small sample of PMRs required per QI.

\section{Its role in the context of development of EMR system}

The above method is a powerful means of implementing an authoritative and valid national QI system, in both developed and developing countries, before EMRs become the norm. As attempts to adopt EMRs have faced several barriers, EMR introduction and adoption at a national level may well take longer than expected. ${ }^{12}$ In addition, the quality of the data that can be systematically extracted automatically is limited by both technical (IT system compatibility in hospitals) and ethical (confidentiality of information) obstacles to even partial EMR systems. ${ }^{28}$ Without hampering the development of EMRs and the meaningful use of health information technology, our PMR-based method represents a pragmatic alternative. Importantly, this method may be used in countries with complete paper 
records, as well as countries with mixed paper and electronic records. We recognise that even in nations with relatively high EMR adoption, often hospitals use both electronic and paper records. This methodology can be applied to the manual extraction of data from EMRs as needed, and act as a bridge to measuring quality in hospitals on a national level pending complete adoption of electronic systems. It is particularly well suited to practice guidelines, organisational issues related to the standardisation of work rules and coordination, and could also be used to assess the quality of patient care pathways. ${ }^{29}$

Acknowledgements We thank members of the COMPAQH team and the hospital representatives who took part in the project. We thank HAS for use of their database. Further details are available on the COMPAQH and HAS websites (http://www.compaqh. fr; http://www.has-sante.fr). The COMPAQH project is supported by the French Ministry of Health and the French National Authority for Health (HAS).

Contributors $\mathrm{MC}$ has made substantial contribution to design of the manuscript, has been involved in the drafting and was responsible for the interpretation and statistical analysis of the data. HL and GN were involved in the drafting of the manuscript and brought important intellectual content. LM, CS and FC critically revised the manuscript. EM was involved in the conception and drafting of the manuscript, and has given final approval of the version to be published. All authors read and approved the final manuscript.

Funding This work was supported by the French High Authority of Health and the French Ministry of Health.

\section{Competing interests None.}

Provenance and peer review Not commissioned; externally peer reviewed.

Open Access This is an Open Access article distributed in accordance with the Creative Commons Attribution Non Commercial (CC BY-NC 3.0) license, which permits others to distribute, remix, adapt, build upon this work non-commercially, and license their derivative works on different terms, provided the original work is properly cited and the use is noncommercial. See: http://creativecommons.org/licenses/ by-nc/3.0/

\section{REFERENCES}

1 Ireland M, Paul E, Dujardin B. Can performance-based financing be used to reform health systems in developing countries? Bull World Health Organ 2011;89:695-8.

2 Agency for Healthcare Research and Quality. Tutorial on quality measures-desirable attributes of a quality measure. http://www.qualitymeasures.ahrq.gov/tutorial/attributes.aspx (cited Jan 2012).

3 Li L, Young D, Xiao S, et al. Psychometric properties of the WHO Quality of Life questionnaire (WHOQOL-100) in patients with chronic diseases and their caregivers in China. Bull World Health Organ 2004;82:493-502.

4 Kerr EA, Smith DM, Hogan MM, et al. Comparing clinical automated, medical record, and hybrid data sources for diabetes quality measures. Jt Comm J Qual Improv 2002;28:555-65.

5 Liesenfeld B, Heekeren H, Schade G, et al. Quality of documentation in medical reports of diabetic patients. Int $J$ Qual Health Care 1996;8:537-42.

6 Keating NL, Landrum MB, Landon BE, et al. Measuring the quality of diabetes care using administrative data: is there bias? Health Serv Res 2003;38:1529-45.

7 MacLean CH, Louie R, Shekelle PG, et al. Comparison of administrative data and medical records to measure the quality of medical care provided to vulnerable older patients. Med Care 2006;44:141-8.

8 Schneider KM, Wiblin RT, Downs KS, et al. Methods for evaluating the provision of well child care. Jt Comm J Qual Improv 2001;27:673-82.

9 Dresser MV, Feingold L, Rosenkranz SL, et al. Clinical quality measurement. Comparing chart review and automated methodologies. Med Care 1997;35:539-52.

10 Forster M, Bailey C, Brinkhof MW, et al. Electronic medical record systems, data quality and loss to follow-up: survey of antiretroviral therapy programmes in resource-limited settings. Bull World Health Organ 2008;86:939-47.

11 Jha AK, DesRoches CM, Campbell EG, et al. Use of electronic health records in U.S. hospitals. N Engl J Med 2009;360:1628-38.

12 Charles D, Furukawa M, Hufstader M. Electronic Health record systems and intend to attest to meaningful use among non-federal Acute care Hospitals in the United States: 20082011. The Office of the National Coordinator for Health Information Technology, 2012.

13 National Authority for Health. Quality indicators. France: 2012. http://www.has-sante.fr/portail/jcms/c_493937/ipaqssindicateurs-pour-l-amelioration-de-la-qualite-et-de-lasecurite-des-soins (updated 2012; cited Jan 2012).

14 World Health Organization. European health for all database. 2007.

15 Ministry of Health. PLATeforme d'INformations sur les Etablissements de Santé MCO (Médecine, Chirurgie, Obstétrique) et SSR (Soins de Suite et de Réadaptation). France. http://www.platines.sante.gouv.fr/ (cited Jan 2012).

16 Grenier-Sennelier C, Corriol C, Daucourt V, et al. Developing quality indicators in hospitals: the COMPAQH project. Rev Epidemiol Sante Publique 2005;53(Spec No 1):1S22-30.

17 Corriol C, Grenier C, Coudert C, et al. The COMPAQH project: researches on quality indicators in hospitals. Rev Epidemiol Sante Publique 2008;56(Suppl 3):S179-88.

18 Arkin CF, Wachtel MS. How many patients are necessary to assess test performance? JAMA 1990;263:275-8.

19 McGlynn EA, Kerr EA, Adams J, et al. Quality of health care for women: a demonstration of the quality assessment tools system. Med Care 2003;41:616-25.

20 McColl A, Roderick P, Smith H, et al. Clinical governance in primary care groups: the feasibility of deriving evidence-based performance indicators. Qual Health Care 2000;9:90-7.

21 Rubin HR, Pronovost P, Diette GB. From a process of care to a measure: the development and testing of a quality indicator. Int J Qual Health Care 2001;13:489-96.

22 Campbell SM, Braspenning J, Hutchinson A, et al. Research methods used in developing and applying quality indicators in primary care. Qual Saf Health Care 2002;11:358-64. 
23 Corriol C, Daucourt V, Grenier C, et al. How to limit the burden of data collection for quality indicators based on medical records? The COMPAQH experience. BMC Health Serv Res 2008;8:215.

24 Lorenz MO. Methods of measuring the concentration of wealth. Publications of the American Statistical Association 1905;9:209-19.

25 Shortell SM. Continuity of medical care: conceptualization and measurement. Med Care 1976;14:377-91.

26 Hospital Report Research Collaborative. Hospital e-scorecard report 2008: acute care. Canada: Hospital Report Research Collaborative, 2008. http://www.hospitalreport.ca/downloads/
2008/AC/2008_AC_cuo_techreport.pdf (updated 2008; cited $10 \mathrm{Jul} 2009$ ).

27 van Dishoeck AM, Looman CW, van der Wilden-van Lier EC, et al. Displaying random variation in comparing hospital performance. BMJ Qual Saf 2011.

28 Roth CP, Lim YW, Pevnick JM, et al. The challenge of measuring quality of care from the electronic health record. Am J Med Qual 2009;24:385-94.

29 Minvielle E, Leleu H, Capuano F, et al. Suitability of three indicators measuring the quality of coordination within hospitals. BMC Health Serv Res 2010;10:93. 